\title{
DIMENSÕES DE EMPODERAMENTO DE MULHERES MÉDICAS DA SERRA
}

\section{CATARINENSE}

\author{
Talita Granemann Melo ${ }^{1}$ \\ https://orcid.org/0000-0001-5326-7380 \\ Cristina Keiko Yamaguchi ${ }^{2}$ \\ http://orcid.org/0000-0001-7073-4307 \\ Recebido em: 17 mar. 2019 \\ Aceito em: 11 ago. 2020
}

\begin{abstract}
Como citar este artigo: MELLO, T. G.; YAMAGUCHI, C. K. DIMENSÕES DE EMPODERAMENTO
DE MULHERES MÉDICAS DA SERRA CATARINENSE: DIMENSIONS OF EMPOWERMENT OF MEDICAL WOMEN FROM SANTA CATARINA MOUNTAIN RANGE. Revista Visão: Gestão Organizacional, Caçador (SC), Brasil, v. 10, n. 1, p. 39-53, 2021. DOI: 10.33362/visao.v10i1.1946. Disponível em:

https://periodicos.uniarp.edu.br/index.php/visao/article/view/1946
\end{abstract}

Resumo: Até a década de 1960, a medicina no Brasil era exercida majoritariamente por homens. A partir da década de 1970, a circulação as mulheres aumentaram nas faculdades de Medicina, aumentando gradativamente nas décadas seguintes. De uma profissão basicamente dominada pelos homens, a medicina passa a ser uma profissão onde a maioria dos novos médicos licenciados são mulheres. Essa pesquisa objetivou compreender o nível de empoderamento das médicas que atuam na serra catarinense. Os procedimentos metodológicos adotados foram: pesquisa descritiva, estudo de caso, com abordagem qualitativa. A pesquisa foi realizada com 15 médicas que atuam na serra catarinense. Foi utilizado um questionário com roteiro semiestruturado, contemplando as dimensões de empoderamento individual, relacional e coletiva. Buscou-se conhecer os principais desafios enfrentados pela mulher na área da saúde, gerando repercussão na organização e dinâmica do trabalho. Os resultados apontam que houve destaque para a dimensão individual e relacional, visto que, as entrevistadas apontaram fortemente os seguintes objetivos: (1) ser referência na área de atuação; (2) ser reconhecida pelo trabalho que executa, (3) ser ética e útil para a sociedade; (4) alcançar novos patamares na carreira; (5) ter muitos pacientes; (6) ter poder de aquisição de bens materiais; (7) descobrir o seu propósito na vida dentro da profissão e evoluir como ser humano; (8) ocupar cargos importantes; (9) trabalhar no que ama. Os resultados mostram que a atuação na docência no ensino superior contribui para melhorar o seu empoderamento, quando seis médicas afirmam que se sentem referência pelo seu exemplo profissional para futuras médicas.

\footnotetext{
1 Graduanda do curso de Medicina na Universidade do Planalto Catarinense - UNIPLAC. E-mail: tali31@outlook.com.

2 Doutora em Engenharia e Gestão do Conhecimento. Docente do Programa de Pós-Graduação em Ambiente e Saúde na Universidade do Planalto Catarinense - UNIPLAC. E-mail: criskyamaguchi@gmail.com.
} 
Palavras-Chave: Empoderamento feminino, medicina, mercado de trabalho.

\section{DIMENSIONS OF EMPOWERMENT OF MEDICAL WOMEN FROM SANTA CATARINA MOUNTAIN RANGE}

Abstract: Until the 1960s, medicine in Brazil was mainly exercised by men. From the 1970s onwards, the movement of women in medical schools increased and grew gradually over the following decades. In principle a career basically dominated by men, medicine becomes a profession where the majority of new licensed doctors are women. This study intends to understand the level of empowerment of the female doctors who work in the Santa Catarina Mountain Range and adopted descriptive research and case study, with a qualitative approach, as methodological procedures. The research was carried out with 15 female doctors who work in the Santa Catarina Mountain Range and used a semi-structured questionnaire, including the dimensions of individual, relational e collective empowerment. The research sought to know the main challenges faced by women in the area of health, generating repercussions on the organization and work dynamics. The results emphasized the individual and relational dimensions, since the interviewees strongly pointed out the following objectives: (1) be a reference in the area of operation; (2) be recognized for her work; (3) be ethical and useful to the society; (4) achieve new career levels; (5) have many patients; (6) have purchasing power of material goods; (7) discover your purpose in life within the profession and evolve as a human being; (8) hold important job positions; (9) work on what you love. Results prove that teaching in higher education contribute to improve their empowerment when six female doctors state that they see themselves as a reference for future female doctors by their professional example.

Keywords: Women's empowerment, medicine, job market.

\section{INTRODUÇÃO}

Historicamente, ao analisar os papéis femininos e masculinos, desde os primórdios o homem esteve relacionado ao mundo do trabalho na esfera pública, enquanto à mulher coube o papel reprodutivo e de cuidadora do lar (VELHO, 2011).

Tradicionalmente até a década de 1960, a medicina no Brasil era exercida majoritariamente por homens (BECKER; GEER; HUGHES; STRAUSS, 2005). Foi somente a partir da década de 1970 que as faculdades de Medicina passaram a ser um espaço de maior circulação das mulheres, aumentando gradativamente ao longo das décadas de 1980 e 1990 e mais aceleradamente na primeira década do século XXI.

Nas últimas décadas, tem se rompido o hiato de gênero que durante séculos, cerceou a entrada das mulheres na profissão médica. De uma profissão basicamente dominada pelos homens, a medicina passa a ser uma profissão onde a maioria dos novos médicos licenciados 
são mulheres (ÁVILA, 2014).

Uma pesquisa que comparou os impactos do aumento de profissionais femininas na medicina em quatro países de língua inglesa (Estados Unidos, Canadá, Reino Unido e Austrália) constatou que médicos e médicas não constroem a carreira da mesma maneira. Há diferenças de padrões e na escolha da especialidade entre os sexos que afetarão o futuro planejamento dos recursos de mão de obra médica (ÁVILA, 2014).

A discriminação encontra-se enraizadas na cultura médica e fazem com que homens e mulheres não estejam em situação de igualdade. A diferença de gênero apresentase por meio de barreiras (diretas e indiretas) que impedem as mulheres de ascender na carreira em condições de igualdade com os homens e reproduzem espaços de formação demarcados por sexo (HIRATA; KERGOAT, 2003).

A palavra empoderamento é a tradução do termo inglês empowerment, denota no processo de ganhar poder para lutar e defender seus direitos. No caso das mulheres, o empoderamento encontra-se alicerçada em alcançar a igualdade e oportunidades, por meio da emancipação, de ter escolhas sobre sua vida, escolher onde deseja trabalhar, com quem deseja construir uma família etc. O empoderamento não é exclusivamente social ou exógeno, não se trata da independência de agentes externos ou autores, ou seja, as variáveis da sociedade podem influenciar ou impulsionar na formação da mulher nos processos de poder (SOUZA; MELO 2009).

Nesse contexto, esse estudo justifica-se pela relevância em compreender o nível de empoderamento das médicas que atuam na serra catarinense.

O trabalho encontra-se estruturado da seguinte forma: na seção 1 a introdução; na seção 2 o referencial teórico que abordam o empoderamento feminino e as dimensões do empoderamento feminino; na seção 3 a metodologia; na seção 4 a apresentação e análise dos dados; na seção 5 as considerações finais e na seção 6 a lista de referências utilizadas no trabalho. 


\section{REFERÊNCIAL TEÓRICO}

\section{EMPODERAMENTO FEMININO}

O empoderamento ocorre quando os indivíduos, organizações e comunidades obtém oportunidades e que tenham a capacidade de agirem e decidirem em seu âmbito social (SOUZA; MELO 2009). Pilonieta (2002) afirma que para o empoderamento acontecer, necessita de uma mudança política e comunitária que evidencie uma valorização daqueles que não são reconhecidos e que estão silenciados para que possam mostrar suas potencialidades. As pessoas desprovidas de poder começam uma mudança de vida obtendo o controle de suas vidas, descobrindo suas habilidades e assumindo seus próprios compromissos (LÉON, 2000).

Nas relações de gênero durante muito tempo a mulher esteve sujeita ao sistema de domínio patriarcal, este sistema começou a mudar com o empoderamento da mulher que trouxe transformações para si própria (COSTA, 2008). Segundo Baquero (2012), o empoderamento surgiu com a reforma protestante, porém apenas eclodiu na segunda metade do século XX com os movimentos emancipatórios de feministas na luta por seus direitos civis nos países desenvolvidos. Para Lisboa (2002) o empoderamento da mulher iniciou dentro de sua própria casa, espaço onde ocorrem as relações do cotidiano no qual está diretamente relacionada ao desenvolvimento dos seus sentimentos de autoestima e autoconfiança. Foi então que, no final do século XX, o empoderamento se tornou objeto central de estudos, com o conceito de participação e integração das pessoas no processo de desenvolvimento de suas habilidades e conhecimentos (LISBOA, 2007).

O termo empoderamento trata-se de um processo que faz com que os indivíduos utilizem suas habilidades e conhecimentos para atuar nas tomadas de decisões com autonomia, autoridade e responsabilidade (OLIVEIRA; RODRIGUEZ, 2004). O empoderamento busca potencializar as pessoas e compreender a capacidade individual e coletiva de sua asserção para tomadas decisões, nos diversos níveis da sociedade (LISBOA, 2008). Permite que a pessoa seja capaz de mudar o seu comportamento e nos meios em que trabalha (FESTE; ANDERSON, 1995). De acordo com Oakley e Clayton (2003), empoderamento pode se apresentar nos indivíduos em três áreas. Como o poder da pessoa por meio de uma maior confiança em sua própria capacidade, poder através do aumento de relações das pessoas estabelecidas com outras 
organizações e um poder resultante do acesso aos recursos econômicos. Lisboa (2008) conclui então que empoderamento está inteiramente interligado com a participação dos indivíduos e vem sendo evidenciado em diversos lugares no mundo. Ávila (2007) afirma que a entrada das mulheres tem demonstrado isto com a entrada nos mais diversos âmbitos da sociedade.

Para Oliveira et al (2015) as mulheres acreditam que o sucesso e bem-estar estão relacionados com o fazer o que gosta e conseguem relacionar os objetivos pessoais com os profissionais. Nos estudos realizados por Oliveira et al (2015), os sinais de empoderamento ficaram visíveis, no momento que as mulheres participam nos processos decisórios, por poderem participar ao andamento das estratégias institucionais.

De acordo com estudos de Santos; Dias e Pacheco (2018), as mulheres declaram que foi necessária persistência para atingir suas metas e a consciência de que para se sobressair no mercado de trabalho necessitam estudar e se especializar. Nos estudos de Oliveira; Oliveira e Marques (2020), aplicaram o Design Thinking, houve uma contribuição para criação de soluções inovadoras para o empoderamento feminino. Os resultados indicaram uma percepção positiva dos participantes em relação às técnicas abordadas e como aplicá-las no processo do desenvolvimento de soluções tecnológicas, bem como idealizar soluções relacionadas aos temas propostos nas oficinas integrando a tecnologia ao protagonismo feminino.

\section{DIMENSÕES DO EMPODERAMENTO}

Para Horochovski (2006), o empoderamento depende de elementos, sendo um processo em que vários agentes como: empresas, organizações, o Estado entre outras, atuam como um canal interveniente, facilitando, indicando caminhos prováveis e auxiliando em todos os aspectos, nunca ditando as ações a serem feitas, para evitar retaliações bloqueadoras de intuitos. Ainda nesse contexto, o autor afirma que o empoderamento não é o resultado de uma comunidade análoga, que compartilha interesses semelhantes, pelo contrário, é o fruto de interesses e ações conflituosas por recursos.

No documento intitulado Princípios de Empoderamento das Mulheres (ONU MULHERES, 2010, p. 21), empoderamento é definido como "dar ou adquirir poder ou mais poder. [...] Uma ampliação da liberdade de escolher e agir, ou seja, o aumento da autoridade e do poder dos indivíduos sobre os recursos e decisões que afetam suas próprias vidas". Neste 
sentido, o indivíduo que se encontra empoderado tem a capacidade de traçar seus propósitos, reconhecer ou ampliar suas competências, deliberar conflitos e sustentar a si próprio, sendo este um processo e resultado concomitantemente, podendo ser empoderadas pessoas desprivilegiadas financeiramente, mulheres, indivíduos da raça negra e indígenas, todos aqueles indivíduos que não têm liberdade para tomar suas próprias decisões e aqueles que são desfavorecidos na sociedade.

De acordo com Mageste, Melo e Ckagnazaroff (2008), o empoderamento feminino é um tema recente, e compreende o fator de poder das mulheres a respeito das decisões sobre suas vidas tanto no âmbito público quanto no privado, assim como a detenção de poder nas tomadas de decisões em acontecimentos públicos e privados que tenham interferência direta ou indireta na sociedade ou seus próprios interesses particulares. O processo de empoderamento das mulheres tem ganhado espaço no campo de discussões acadêmicas nos últimos anos, porém devido a inexistência de uma teoria estruturada, existem dificuldades para que se tenha discussões mais aprofundadas, e, portanto, o conceito do processo do empoderamento ainda é considerado um tanto vago.

Seguindo esta linha, Mageste, Melo e Ckagnazaroff (2008) propõem um processo de empoderamento que consiste em três níveis: 1) o nível de análise individual, no qual ocorre o ponto de partida para o empoderamento: partindo de um objetivo pessoal e da apropriação de autonomia, neste nível, a mulher passa a enfrentar os obstáculos que encontra. 2) O segundo nível, chamado de processo relacional, empoderamento feminino tem envolvimento direto com outros elementos que compõem o cenário em que a mulher está inserida. Neste nível, fatores como influência familiar, valores culturais transmitidos durante a criação na infância e juventude, e principalmente a educação formal recebida. É por meio da educação que a mulher adquire habilidades e autoconfiança para poder atuar no mercado de trabalho e atingir a emancipação, alcançar cargos e salários mais altos nas empresas, participar como representantes no governo e obter influência política. 3) O terceiro nível, o nível contextual, analisa o empoderamento, engloba uma quantidade de temas e estão relacionadas as questões de saúde, bem-estar, nutrição adequada, sexualidade e reprodução, representação equitativa das mulheres na carreira política, na formulação de políticas públicas que impactam a sociedade na qual estão inseridas, na participação da mulher na economia e a inserção no mercado de 
trabalho.

Estes três níveis trabalham de uma forma interligada e dependente, pois a ação em um gera mudança no outro, em que "uma transformação radical na estrutura de poder que mantém essa estrutura é lenta e gradual, incorporando aos poucos os resultados" (MAGESTE; MELO; CKAGNAZAROFF, 2008, p. 7). O processo de empoderamento pode ser iniciado em qualquer um dos níveis supracitados, mas só é considerado completo quando passar por todos eles.

\section{METODOLOGIA}

Visando compreender o processo de empoderamento das profissionais médicas na serra catarinense, os procedimentos metodológicos adotados foram:

Quadro 1 - Procedimentos metodológicos

\begin{tabular}{|l|l|}
\hline Quanto à natureza/ Meio de investigação & Pesquisa de campo \\
\hline Abordagem & Qualitativa \\
\hline Tipo de pesquisa quanto aos objetivos & Descritiva \\
\hline Técnica de coleta de dados & Entrevista roteiro semiestruturado \\
\hline Técnica de análise de dados & Dimensões de Empoderamento: Individual, Relacional e Coletiva \\
\hline
\end{tabular}

Fonte: Elaborado pelos autores (2018)

A revisão da literatura trouxe maior compreensão do conteúdo das dimensões, baseados em Rowlands $(1995,1997)$ e foram sistematizadas três dimensões de empoderamento para realizar a análise dos dados.

Quadro 2 - Dimensões do empoderamento adotadas para a análise dos dados

\begin{tabular}{|l|l|}
\hline Dimensão & Descrição \\
\hline Individual & $\begin{array}{l}\text { Neste nível surge a percepção da posição desprivilegiada, e a partir disso, iniciam-se novos } \\
\text { comportamentos e processos para o desenvolvimento de autoconfiança, autonomia, } \\
\text { independência, e liberdade, buscando a reversão das implicações resultantes da opressão } \\
\text { internalizada e influenciar e modificar o direcionamento das ações que Ihe diz respeito. }\end{array}$ \\
\hline Relacional & $\begin{array}{l}\text { Implica o envolvimento e participação de todos os relacionamentos, influências sociais e } \\
\text { alianças estabelecidas que servissem de base para a construção do empoderamento do } \\
\text { indivíduo, assim como a capacidade do indivíduo de influenciar e negociar com tais elementos } \\
\text { para que se possa atingir o empoderamento. }\end{array}$ \\
\hline Coletivo & $\begin{array}{l}\text { O momento e que o indivíduo acredita que pode contribuir para a sociedade (individualmente } \\
\text { ou juntamente com outros grupos) e se sente responsável pela melhoria coletiva. A partir } \\
\text { disso, passa trabalhar para estender, compartilhar e participar de ações de melhorias, } \\
\text { estratégias e responsabilização no panorama da sociedade na qual está inserido. }\end{array}$ \\
\hline
\end{tabular}

Fonte: Elaborado com base em Rowlands (1995,1997), Horochovski (2006), Mageste, (2008), Mageste, Melo e Ckagnazaroff (2008), Kleba e Wendausen (2009) 
Com relação ao local da pesquisa, foi realizada uma pesquisa de campo com um grupo de mulheres que atuam como médicas na serra catarinense.

Fez se necessário a apropriação dos conhecimentos referentes ao processo de empoderamento da mulher. Assim, foi realizado o levantamento bibliográfico sobre a participação feminina nas esferas social, educacional e profissional, a fim de construir um questionário apropriado aos objetivos desta pesquisa para a área médica.

Foram consideradas para essa amostra, as 15 mulheres que atuam em Lages como médicas, correspondendo a 75\% da amostra, visto que, cinco médicas que foram convidadas e não devolveram os questionários respondidos. A técnica de abordagem escolhida foi qualitativa e o objetivo descritivo. Para a coleta de dados utilizou-se um questionário semiestruturado, mantendo o sigilo da identidade das respondentes.

O questionário foi estruturado em quatro blocos de questões, sendo os dois primeiros blocos com questões objetivas ou de múltipla escolha e os dois últimos, discursivos: 1으 bloco): perfil da entrevistada, destinado a caracterizar as integrantes da amostra segundo a faixa etária, estado civil, maternidade, especialização, meios de aprendizado sobre gerência e aquisição de novos conhecimentos; 2 으 bloco): sobre tempo de atuação no mercado e gerência de clínica ou consultório, caso atuassem nesse ambiente de trabalho; 3ํ bloco): questões sobre bem-estar, sucesso profissional, reconhecimento, ascensão profissional e processos decisórios; e 4으 bloco): a partir da experiência própria médica, solicitou-se sugestões para as jovens médicas se empoderarem no mercado de trabalho.

\section{APRESENTAÇÃO E ANÁLISE DOS RESULTADOS}

O presente estudo buscou contribuir apresentando um panorama do empoderamento da mulher médica em Santa Catarina, tendo em vista a escassez de estudos com este propósito. O que se vê, em termos de produção científica, é iniciativas isoladas com propósitos distintos a esse estudo. Outro ponto digno de nota é a possibilidade da compreensão, além da identificação do perfil das profissionais médicas da serra catarinense, sobre os níveis de aprendizagem e empoderamento profissional. Esse último é relevante nos dias atuais, tendo em vista que a mulher começa a atuar em diferentes espaços na sociedade, tendo repercussão na organização e dinâmica do trabalho. 
Não obstante aos aspectos supracitados, vale ainda mencionar, que ainda se desconhece a participação da força de trabalho e tino empreendedor da mulher médica catarinense e sua contribuição para o desenvolvimento socioeconômico desta unidade da federação. O que se sabe é que Santa Catarina possui forte representatividade na economia brasileira, porém a distinção da força empreendedora do gênero, ainda se desconhece.

Quadro 3 - Áreas de atuação das médicas respondentes:

\begin{tabular}{|l|l|}
\hline Área de atuação & Quantidade \\
\hline Medicina da Família e Comunidade & 06 \\
\hline Pediatria & 2 \\
\hline Oncologia & 1 \\
\hline Dermatologia & 2 \\
\hline Ginecologia e Obstetrícia & 3 \\
\hline Medicina do Trabalho & 1 \\
\hline TOTAL & 15 \\
\hline
\end{tabular}

Fonte: dados da pesquisa

Em relação ao estado civil, $60 \%$ das médicas são casadas, $26,7 \%$ são solteiras e 13,3\% em união estável. Das médicas estudadas, 53,3\% não possuem filhos, enquanto que 46,7\% possuem de 1 a 3 filhos. A média de idade variou entre 36,9 e 42,6 anos.

Em relação à formação profissional médica, 60\% das médicas possuem residência completa, $20 \%$ além de possuírem residência completa, cursaram o mestrado, e as outras $20 \%$ encontravam-se realizando a residência no momento da pesquisa.

Dentre as 15 profissionais, 10 possuem consultório médico ou eram sócias em uma clínica. Dessas 10 médicas, 50\% atuam no mercado à menos de 5 anos, 20\% entre 6 e 10 anos e 30\% há mais de 20 anos.

As razões para iniciar seu consultório/clínica, foram: 8 médicas responderam "poder fazer o que gosta, 6 médicas pela oportunidade, 4 médicas pela realização de um sonho, 3 médicas pela necessidade e 1 médica para poder trabalhar do seu jeito".

Todas as médicas afirmam que é um desafio buscar atualizações para novos conhecimentos, em virtude da falta de uma sistemática para coleta, organização e divulgação da informação como um empecilho, corroborando com Santos; Dias e Pacheco (2018). Quando buscam se atualizar, é realizado por meio de: leituras individuais, cursos, congressos, simpósios, 
websites do governo, revistas especializadas, artigos, associativismo, reuniões sobre casos clínicos, etc. Afirmam ainda, que as atualizações visam: melhorar o desempenho profissional, melhorar os processos internos do ambiente de trabalho, servem de subsidio para inovações nas atividades do trabalho e divulgação junto aos colegas de profissão.

Quando abordadas sobre o significado de bem estar e sucesso profissional, as respostas foram: (1) fazer um trabalho de qualidade e ter qualidade de vida naquilo que trabalha; (2) alcançar a realização pessoal e sentir-se bem com a função que exerce; (3) realizar plenamente sua atividade profissional, conciliando trabalho e vida pessoal; (4) obter reconhecimento profissional por colegas e pacientes, organizar bem a vida pessoal e profissional; (5) alcançar a ascensão profissional, receber admiração dos colegas da classe e ser feliz na profissão; (6) realizar um diagnóstico eficaz e obter a cura no tratamento do paciente; (7) ter em todos os aspectos da vida uma sensação de dever cumprido, harmonia e felicidade; (8) sentir-se feliz durante os períodos de trabalho e perceber que está sendo útil àqueles que te procuram; (9) realizar um trabalho bom e gratificante, que me permita também contemplar outras esferas da vida (pessoal, atividade física, espiritualidade); (10) poder conciliar família e trabalho de maneira harmônica, onde consiga me dedicar a outros, dentro de suas necessidades e de meus julgamentos; (11) paz de espírito; (12) ser reconhecida e valorizada na minha profissão e (13) fazer diferença na qualidade de vida do paciente e me manter com o meu trabalho.

Quanto a caracterização de ascensão profissional, obteve-se os seguintes resultados: (1) ser referência na área de atuação; (2) ser reconhecida pelo trabalho que executa, (3) ser ética e útil para a sociedade; (4) alcançar novos patamares na carreira; (5) ter muitos pacientes; (6) ter poder de aquisição de bens materiais; (7) descobrir o seu propósito na vida dentro da profissão e evoluir como ser humano; (8) ocupar cargos importantes; (9) trabalhar no que ama.

Nos relatos sobre como foi a trajetória de ascensão profissional 5 médicas relataram de forma objetiva, citando etapas como vestibular-faculdade-residência- empregos, 4 priorizaram bastante a dedicação e busca constante de conhecimentos, 3 expuseram dificuldades e obstáculos citando preconceito e desconfiança quanto ao trabalho feminino e 3 afirmaram estarem ainda em busca da ascensão. Esse resultado corrobora com Hirata e Kergoat (2003), quando afirma que a discriminação se encontra enraizadas na cultura médica e fazem com que homens e mulheres não estejam em situação de igualdade. A diferença de gênero apresenta- 
se por meio de barreiras (diretas e indiretas) que impedem as mulheres de ascender na carreira em condições de igualdade com os homens e reproduzem espaços de formação demarcados por sexo.

Quanto ao reconhecimento por mérito, 11 médicas indicaram conquista por mérito próprio por dedicação (uma se sentia desqualificada no início por julgamento de outros colegas e outra se sente privilegiada, apontou a sua situação social como responsável pela diversidade de escolha), 3 se consideram no caminho de serem reconhecidas devido ao início de carreira, 1 indicou por falta de profissional da área dela.

Baseado em Souza e Melo (2009), o empoderamento feminino encontra-se alicerçada em alcançar a igualdade e oportunidades, por meio da emancipação, de ter escolhas sobre sua vida, escolher onde deseja trabalhar, com quem deseja construir uma família etc., retrata a fala de algumas entrevistas, quando afirmam que ... "percebia uma desigualdade na área cirúrgica" .... "Percebo machismo vindo de pacientes de ambos os sexos e colegas homens". empoderamento não é exclusivamente social ou exógeno, não se trata da independência de agentes externos ou autores, ou seja, as variáveis da sociedade podem influenciar ou impulsionar na formação da mulher nos processos de poder.

Constatou-se que o empoderamento feminino das médicas entrevistadas foi fruto de algumas ações, como: potencializar sua capacidade individual e coletiva, se destacar no meio em que atua, superar as diferenciais no ambiente de trabalho e de seus pacientes, abertura de oportunidade profissional, buscar seu sonho, compartilhar experiência, apoio a iniciativas que empoderam outras mulheres e valorizar as profissionais com quem atua (FESTE, ANDERSON, 1995; OAKLEY, CLAYTON, 2003; ÁVILA, 2007; LISBOA, 2008).

As entrevistadas recomendam às futuras médicas que: (1) jamais permitir que o desrespeito, a intimidação e crítica masculina; (2) tratar todos com respeito e profissionalismo; (3) persistência e paciência; (4) sempre se posicionar e valorizar seu espaço e mercado de trabalho; (5) ser determinada, sonhadora e não ter limites para vencer obstáculos; (6) mantenha postura madura, firme e atualizada; (7) não ter medo de se destacar e (8) nunca desista, pois, tudo é possível.

As médicas afirmam que o grande desafio é lidar com a dupla jornada de trabalho e relação com a família, nove médicas relataram dificuldade em conciliar devido à alta carga 
horária, desgastando física e emocionalmente, e muitas vezes sacrificando tempo com a família em nome da profissão. Quatro médicas relataram conseguir manter um bom equilíbrio entre vida profissional e social, delegando funções, e duas médicas não responderam a essa questão. Esse resultado vem de encontro com estudos de Mageste, Melo e Ckagnazaroff (2008), quando afirmam que o fator de poder das mulheres a respeito das decisões sobre suas vidas tanto no âmbito público quanto no privado, assim como a detenção de poder nas tomadas de decisões em acontecimentos públicos e privados que tenham interferência direta ou indireta na sociedade ou seus próprios interesses particulares.

Nessa pesquisa, as dimensões de empoderamento abordados por Rowlands (1995,1997), Horochovski (2006), Mageste, (2008), Mageste, Melo e Ckagnazaroff (2008), Kleba e Wendausen (2009), Oliveira et al., (2015), destacou a dimensão individual, visto que, as entrevistadas apontaram fortemente os seguintes objetivos: (1) ser referência na área de atuação; (2) ser reconhecida pelo trabalho que executa, (3) ser ética e útil para a sociedade; (4) alcançar novos patamares na carreira; (5) ter muitos pacientes; (6) ter poder de aquisição de bens materiais; (7) descobrir o seu propósito na vida dentro da profissão e evoluir como ser humano; (8) ocupar cargos importantes; (9) trabalhar no que ama.

Os resultados mostram que a atuação na docência no ensino superior contribui para melhorar o seu empoderamento, quando seis médicas afirmam que se sentem referência pelo seu exemplo profissional para futuras médicas.

\section{CONSIDERAÇÕES FINAIS}

Constatou-se que para a maioria das médicas a realização profissional está vinculada ao reconhecimento dentro de suas áreas e uma dificuldade seria conseguir equilibrar tempo de qualidade entre trabalho e família. Percebe-se pouca aspiração por cargos de chefia. A amostra mostrou-se bem amparada no apoio familiar e no incentivo a independência financeira, além de bem atualizada.

Ao falar sobre a forma como homens as veem profissionalmente, praticamente metade do grupo estudado optou por não responder, sendo que as médicas que responderam, 2 delas exprimiram sua percepção de desigualdade. Isso denota uma dimensão individual ao passo que essas 2 médicas tiveram a percepção de posição desprivilegiada. 
Quanto as sugestões para empoderamento, a maioria priorizou a independência, persistência e livre arbítrio. Isso denota uma dimensão individual de empoderamento, demonstrando o direcionamento de ações pautadas em desenvolvimento de autonomia, autoconfiança e liberdade.

Na colaboração para o crescimento de outras mulheres e ser referência, além da participação em processos decisórios, é perceptível os níveis de dimensão de empoderamento relacional e coletivo, pois implica em capacidade de influenciar e negociar para se atingir o empoderamento, também por acreditarem poder contribuir para a sociedade e compartilhar no panorama em que está inserida.

O presente estudo tem como contribuição científica principal a apresentação de um panorama do empoderamento da mulher médica em Santa Catarina, tendo em vista a escassez de estudos com este propósito. O que se vê, em termos de produção científica, são iniciativas isoladas com propósitos distintos a esse estudo. Outro ponto digno de nota é a possibilidade da compreensão, além da identificação do perfil das profissionais médicas da serra catarinense, sobre os níveis de aprendizagem e empoderamento profissional. Esse último é relevante, tendo em vista que a mulher começa a atuar em diferentes espaços na sociedade, tendo repercussão na organização e dinâmica do trabalho.

Sugere-se para estudos futuros, que a pesquisa possa ser aplicada para mulheres que atuam em diferentes segmentos de atividades ou negócios no mercado de trabalho.

\section{REFERÊNCIAS}

ÁVILA, R. C. Formação das Mulheres nas Escolas de Medicina. Revista Brasileira de Educação Médica, 14238 (1) : 142-149; 2014.

BAQUERO, R. V. A. Empoderamento: Instrumento de emancipação social? Uma discussão conceitual. Revista Debates, v.6, n.1, p. 173-187, 2012.

BECKER H.S; GEER, B; HUGHES, EC; STRAUSS, A.L. Boys in White: student culture in medical school. 9. ed. New Brunswick and London: Transaction Publishers, 2005.

BRASIL. Lei no 9.100, de 29 de setembro de 1995. Estabelece normas para a realização das eleições municipais de 3 de outubro de 1996, e dá outras providências. Disponível em: <http://www.planalto.gov.br/ccivil_03/leis/L9100.htm.> Acesso em: 16 out. 2016.

COSTA, A. A. Gênero, poder e empoderamento das mulheres. 2008, 9p. Disponível em: 
<http://www.agende.org.br/docs/File/dados_pesquisas/feminismo/Empoderamento\% 20\%20Ana\%20Alice.pdf>. Acesso em: 19 nov. 2018.

DALL'AVA-SANTUCCI. Mulheres e Médicas: as pioneiras da Medicina. Rio de Janeiro: Ediouro, 2005.

FESTE, C.; ANDERSON, R. M. Empowerment: from philosophy to practice. Patient Education and counseling, v. 26, p 139-144, 1995

FREIRE, P.; SHOR, I. Medo e ousadia: O cotidiano do professor. 5. ed. Rio de Janeiro: Paz e Terra, 1996.

GROSSI, M.P.; MIGUEL, S. Transformando a diferença: as mulheres na política. Revista Estudos Feministas, v. 9, n. 1, p. 167-206, 2001.

HIRATA, H; KERGOAT, D. A divisão sexual do trabalho revisitada. In: Maruani M, Hirata H (Orgs.). As novas fronteiras da desigualdade: homens e mulheres no mercado de trabalho. São Paulo: Senac, 2003. p. 111-123

HOROCHOVSKI, R.R. Empoderamento: definições e aplicações. Encontro anual da ANPOCS, v. 30, p. 1-29, 2006.

KLEBA, M.E.; WENDAUSEN, A. Empoderamento: processo de fortalecimento dos sujeitos nos espaços de participação social e democratização política. 2009. Disponível em: < http://www.scielo.br/pdf/sausoc/v18n4/16.pdf>. Acesso em: 26 set. 2016.

LEÓN, M. Empoderamiento: Relaciones de las mujeres con el poder. Estudos Feministas, v.8, n.2, p. 191-205, 2000

LISBOA, T. K. Empoderamento. In: CONFERÊNCIA ESTADUAL DOS DIREITOS DA MULHER, 2. 2007, Florianópolis, SC. Anais... Florianópolis, 2007. Disponível em: < http://www.slideserve.com/kirk/ii-confer-ncia-estadual-dos-direitos-da-mulherflorian-polissanta-catarina-12-e-13-de-julho-de-2007>. Acesso em: 2 out. 2018.

LÜCHMANN, L. H. H.; ALMEIDA, C. C. R. A representação política das mulheres nos Conselhos Gestores de Políticas Públicas. Revista Katálysis, v. 13, n. 1, p. 86-94, 2010.

MAGESTE, G.S.; MELO, M.C.O.L.; CKAGNAZAROFF, I.B. Empoderamento de mulheres: uma proposta de análise para as organizações. $V$ Encontro de Estudos Organizacionais da ANPAD. Belo Horizonte / MG. 18 a 20 jun. 2008.

MIGUEL, S.M.A política de cotas por sexo: um estudo das primeiras experiências no legislativo brasileiro. Centro Feminista de Estudos e Assessoria, 2000. Disponível em: < file:///D:/artigos\%20para\%20TCC/a_politica_de_cotas_por_sexo\%20CEFEMEA.pdf>. Acesso em: 16 set. 2016.

OAKLEY, P.; CLAYTON, A. Monitoramento e avaliação do empoderamento ("empowerment"). São Paulo, Instituto Pólis, 2003. 96 p. 
OLIVEIRA, K.B.; LOPES, G.S.C.; WATANABE, M.; YAMAGUCHI, C.K.; DUARTE, R. Estudo do empoderamento na perspectiva de mulheres líderes. Pretexto. V. 16, n. 4, p. 82-99.

OLIVEIRA, L.M.C.; OLIVEIRA, R.A.; MARQUES, A.B. Design Thinking: oficinas para inovação e empoderamento feminino. 2020: ANAIS DO XIV WOMEN IN INFORMATION TECHNOLOGY ARTIGOS CURTOS. Disponível em: <https://sol.sbc.org.br/index.php/wit/article/view/11295>. Acesso em 06 set. 2020,

OLIVEIRA, U. R.; RODRIGUEZ, M. V. R. Empowerment como ferramenta de gestão de pessoas para a redução dos custos e aumento da eficiência operacional: Um estudo de caso em uma instituição financeira. In: ENCONTRO NACIONAL DE ENGENHARIA DE PRODUÇÃO, 24, 2004, Florianópolis. Anais eletrônicos... Florianópolis: ABEPRO, 2004. Disponível em: <http://www.abepro.org.br/biblioteca/ENEGEP2004_Enegep0707_0033.pdf>. Acesso em: 3 out. 2018.

ONU MULHERES. Entidade das Nações Unidas para a igualdade de gênero e o Empoderamento das mulheres. Princípios de empoderamento das mulheres: igualdade gera negócios. 2010. Brasília. Disponível em: < http://www.onumulheres.org.br/wpcontent/uploads/2016/04/cartilha_WEPs_2016.pdf>. Acesso em: 09 set. 2018.

PDIC 2022 - Programa de Desenvolvimento Industrial Catarinense. 2014. Disponível em:< http://www4.fiescnet.com.br/pt/o-programa-pedic-2022/o-programa>. Acesso em: 20 mar. 2018.

PILONIETA, A. S. Dispositivos de empoderamiento para el desarrollo psicossocial. Revista Universitas Psychologica, v.1, n.2, p. 39-48, 2002

ROWLANDS, J. Empowerment examined: an exploration of the concept and practice of women's empowerment in Honduras. 1995. $289 \mathrm{f}$. Tese (Doutorado em Filosofia) - Durham University, Durham, 1995. Disponível em: < http://etheses.dur.ac.uk/1424/>. Acesso em: 01 mar. 2017.

ROWLANDS, J. Questioning empowerment: Working with women in Honduras. Oxfam, 1997.

SANTOS, M.F.; DIAS, N.N.; PACHECO, L. Empoderamento, liderança e mulher nos processos de trabalho. Conference: XXI SemeAd - Seminários em Administração. At: FEA-USP - São Paulo. Volume: 21

SOUSA, R. M. B. C.; MELO, M. C. O. L. Mulheres na gerência em tecnologia da informação: análise de expressões de empoderamento. Revista de Gestão USP, v.16, n.1, p.1-16. 2009. Disponível em: <http://www.revistas.usp.br/rege/article/view/36658/39379>. Acesso em: 01 fev. 2019.

VELHO, B.T.M. Equidade de gênero no mundo do trabalho: A história de uma organização. In: CONGRESSO NACIONAL DE EXCELÊNCIA EM GESTÃO, 7, 2011, Rio de Janeiro. Anais eletrônicos... Rio de Janeiro: CNEG, 2011. Disponível em: <http://www.excelenciaemgestao.org/Portals/2/documents/cneg7/anais/T11_0452_2137.pd 
f> Acesso em: 15 set. 2016. 